\title{
ANTROPOLOGÍA, ACCIÓN, COLABORACIÓN Y EXPERIMENTACIÓN. Modos de estar en el campo en la praxis etnográfica
}

\author{
Juan R. MÉNDEZ \\ Universidad Nacional de Educación a Distancia \\ juan_r_mendez@hotmail.com
} ANTHROPOLOGY, ACTION, COLLABORATION AND EXPERIMENTATION. Modes of being in the field
in ethnographic praxis

Resumen: Partiendo de varios ejemplos de etnografía aplicada llevados a cabo por el autor, el texto reflexiona sobre la posibilidad de realizar investigaciones comprometidas con determinados problemas sin perder el rigor del enfoque etnográfico. Esta reflexión se produce analizando la relación entre el proceso etnográfico y las subjetividades intervinientes y la imbricación entre conocimiento y acción. A partir de esto se plantea qué significa hacer antropología aplicada y colaborativa, lo que sirve para introducir un marco de investigación-acción que aborda una investigación experimental y militante, donde la etnografía es uno más de los conocimientos que aportar a la praxis realizada dentro del diálogo en el campo.

Abstract: Based on several examples of applied ethnography carried out by the author, the text reflects on the possibility of carrying out research committed to certain problems without losing the rigor of the ethnographic approach. This reflection is produced by analyzing the relationship between the ethnographic process and the intervening subjectivities and the overlap between knowledge and action. From this it is proposed what it means to do applied and collaborative anthropology, which serves to introduce an action-research framework that addresses an experimental and militant research, where ethnography is one more of the knowledge to contribute to the practice carried out within the dialogue in the field.

Palabras clave: Antropología Aplicada. Praxis. Colaboración. Investigación Acción. Antropología Experimental Applied Anthropology. Praxis. Collaboration. Investigation action. Experimental Anthropology 


\section{1.- Introducción}

La temática de la investigación que vengo desarrollando los últimos años fue acordada con Migrapiés, grupo de defensa de derechos de la población migrante de Lavapiés en el que participo desde el año 2011 ${ }^{1}$. En 2014, comenzando mi Trabajo de Fin de Máster (TFM), lo que se convertiría en la primera etapa de mi investigación de doctorado, pensé que la mejor forma de aplicar mi investigación sería ofrecer mi trabajo al grupo y que este eligiera la temática en función de sus intereses. Integrado en sus inicios básicamente por "españoles", Migrapiés había ido creciendo con la incorporación de "africanos" y "bangladesíes"2, atraídos por el trabajo del grupo sobre problemáticas que les afectaban directamente. Este crecimiento hizo que por aquella época aproximadamente el $80 \%$ de los participantes fueran hombres de estos orígenes. Pero la no participación de mujeres "africanas" o "bangladesíes", y la inquietud de parte del colectivo por el desconocimiento sobre las condiciones de estas en Lavapiés, originaron la decisión de que la investigación pudiera servir para pensar cómo ellas podían incorporarse al grupo.

Esta decisión ha condicionado mi trabajo los últimos años, llevándome a una serie de reflexiones sobre qué significa hacer investigación aplicada, las cuales abordo en este texto, que toca debates de largo recorrido en el discurrir antropológico, tales como las diferencias entre antropología aplicada y académica, la colaboración, la investigación acción participante o la experimentación como base del trabajo etnográfico. Para mi exposición partiré de experiencias de mi investigación que relacionan etnografía y acción. Algunas de estas experiencias las asumí en principio como fracasos parciales, pero una vez revisadas me han llevado a pensar si mi sensación de fracaso no se originaba por una mirada demasiado estrecha sobre dos cuestiones: la forma de entender las relaciones que se establecen durante el trabajo de campo y la manera en que pueden llegar a relacionarse conocimiento y acción. Aquí pretendo mostrar que se puede caminar por la tensión que supone hacer etnografía y a la vez intervenir en procesos dialógicos desde un posicionamiento ideológico sin que esto tenga que implicar estudios poco rigurosos. También que la intersubjetividad etnográfica diluye la supuesta polarización entre conocer y actuar: ambas se desarrollan en paralelo y entrelazadas.

Este texto parte de una investigación etnográfica, todavía en marcha, desarrollada principalmente en Lavapiés y centrada en analizar diferentes núcleos de sociabilidad relacionados con la migración y las formas de colectividad producidas, abordando desde aquí formas de imbricar etnografía y acción para producir transformaciones en los entornos analizados. Al hablar de etnografía me refiero a una forma de instrumentalización del cuerpo que, desde la cotidianeidad, permita acceder a las lógicas presentes en el campo (Velasco y Díaz de Rada, 1997). A esta convivencia cotidiana se suman cerca de 40 entrevistas en profundidad entre personas de mi campo y la recogida de documentación para triangular lo recopilado empíricamente. Desde esta investigación, el texto analiza en primer lugar la relación entre el proceso etnográfico y las subjetividades intervinientes en él, planteando la imposibilidad de pensar la etnografía como aséptica y objetiva. La relacionalidad de la praxis etnográfica indica que intervenimos mientras investigamos, queramos o no. La forma en que se realice esta intervención producirá modos de estar en el campo diferenciales y esto conllevará la posibilidad de múltiples formas de colaboración. Esto es analizado en el tercer apartado indicando la posibilidad de que la colaboración se produzca dentro de dinámicas que no estén centradas en la etnografía como elemento principal. Diferentes ejemplos de este tipo de colaboraciones se presentan a continuación para desarrollar una propuesta de etnografía militante y experimental que parta de propósitos de transformación compartidos con las personas en el campo. El texto termina con una reflexión sobre como la moralidad se entrelaza con la propuesta planteada.

\footnotetext{
1 Este texto debe mucho a las discusiones con los participantes en Migrapiés. Sus reflexiones, su participación en la investigación y sus sugerencias han ayudado enormemente a su elaboración.

2 En este texto usaré el entrecomillado cuando me refiera a términos que tienen significados concretos entre los agentes de mi entorno de investigación para llamar la atención sobre su necesaria separación de los términos ét i c que utilizo en mi lógica de investigación. Me estoy refiriendo por tanto a términos é mi c, que serán explicitados en la medida que sean necesarios para la comprensión del texto. Por ejemplo, Con "africanos" me refiero a una autocategorización de los compañeros de Migrapiés. Hablo de personas de África Occidental, de Senegal y otros estados alrededor que con esta forma de definirse tratan de aglutinar la complejidad de procesos como la "etnicidad", la religión o las migraciones familiares, procesos que desbordan el estado nación y hacen muy difícil la identificación en torno a una determinada "nacionalidad"

En cuanto a la construcción de lo "bangladesî", como antigua colonia inglesa y posteriormente de Pakistán, la Guerra de Independencia en 1971 y el uso del bangla como idioma frente al intento de imposición del urdu por parte del gobierno pakistaní se conforman como centralidades principales en la identificación como "bangladesí".

Para más información sobre la perspectiva ét i c - émi c usada en este texto, incluida un revisión crítica de los planteamientos de Marvin Harris, ver Díaz de Rada, 2012
} 
En cuanto a Lavapiés, principal escenario de este texto, es precisamente la migración una de las características que habitualmente se destacan de este barrio en el imaginario madrileño. Tradicionalmente lugar humilde receptor de migración nacional y con una fuerte degradación entre 1970 y 1990, su situación cambia a partir de la década de los 90, debido al proceso de rehabilitación acometido por las administraciones madrileñas y la llegada de jóvenes profesionales y activistas de los movimientos sociales (Cañedo Rodríguez, 2011). A esto se suma el incremento de la migración internacional al barrio en las últimas décadas, a medida que la migración a España aumentaba dentro del periodo económico de crecimiento y Madrid se convertía en una de las ciudades receptoras de mayor población migrante (Dirección General de Inmigración, 2009). Este ha sido el caso de las migraciones "africanas" y "bangladesíes", muy presentes en este texto. Según datos del INE, en la Comunidad de Madrid vivían, en 2003, 2.609 personas nacidas en Bangladesh. En 2014, la cifra se había incrementado a 4.717. De los residentes "bangladesíes" en Madrid, en 2014, 2.646 estaban empadronados en el distrito centro. La población "senegalesa", la mayor de procedencia "africana" en Lavapiés era en 2013 de 2.003 personas. En 2002 sólo había en toda la Comunidad de Madrid 720. La elección de Lavapiés como lugar de residencia tiene que ver con sus características de barrio humilde a la vez que céntrico, lo que combina precios accesibles de alquiler con centralidad dentro de la ciudad.

\section{2.- Un modelo de aplicación de la etnografía. Relacionando subjetividad e intersubjetividad}

El modelo de aplicación en el que basaba mi TFM partía de distinguir mi subjetividad previa, marcada por una intención concreta de acción, de la creación de una lógica de investigación que permitiera una interpretación intersubjetiva reflexiva y metódica de lo observado (Velasco y Díaz de Rada, 1997), limitando en la medida de lo posible sesgos derivados de la intención de intervención. La petición de Migrapiés hacía necesaria una separación entre las lógicas presentes en el grupo (que también eran las mías muchas veces) y el planteamiento de la investigación. Categorías como "participación política" "género" o "nacionalidad" pertenecían a procesos articulativos propios de Migrapiés, de los que había que distanciarse etnográficamente. Como ejemplo, la "participación política" en aquel momento se configuraba en Migrapiés desde el $15 \mathrm{M}^{3}$ y el anarquismo como referentes organizativos principales, enlazados a la vocación de luchar contra ciertas injusticias observadas en el aparato administrativo-estatal en cuanto a racismo y discriminación sobre los migrantes, cuestiones como las redadas policiales por perfil étnico o la existencia de Centros de Internamiento para Extranjeros. Dentro de estos ejes, la "participación" en Migrapiés se definía desde la "solidaridad" y el "apoyo mutuo"4 como formas activistas para cambiar las cosas, siendo la asamblea la forma organizativa. La llegada al grupo de migrantes "bangladesíes" y "africanos" se había producido bajo estos ejes y se esperaba que la incorporación de mujeres de estos orígenes pudiera mantenerse en estos parámetros. Sin embargo, si yo partía de esta forma émic de "participación", mi investigación podía ocultar otras formas de pensar esta, generando tanto la posibilidad de forzar las categorías de Migrapiés sobre la investigación como el riesgo de no tener en cuenta las necesidades y lógicas de estas mujeres.

El deconstruir las lógicas de Migrapiés hizo girar el planteamiento inicial desde cómo conseguir que estas mujeres "participaran" en el grupo a buscar dónde participaban y por qué. De esta manera, el estudio fue esbozado en torno a las condiciones de incorporación (Portes y Böröcz, 1989) en el entorno migratorio y las sociabilidades establecidas en este proceso, dentro de un trabajo que pretendía desarrollar elementos teórico-metodológicos que evitaran el "nacionalismo metodológico" como eje clasificador (Glick Schiller, 2007) para buscar formas de colectividad que no fueran únicamente encaminadas al origen. Así, intersubjetividad y subjetividad previa quedaban entrelazadas y, a la vez, delimitadas. Entendía que la información obtenida con este planteamiento podría ser ofrecida al grupo para que pudiera tomar decisiones que facilitaran el acercamiento a estas mujeres en términos que tuvieran en cuenta los objetivos de Migrapiés. Pero a la vez recoger las necesidades autodefinidas de las dueñas del problema procurando una mediación que no diseñara implementaciones desde "arriba", sino teniendo en cuenta el dialogo de diferentes saberes (Fals Borda, 1999; Weidman, 1978). La investigación podía obtener conocimiento útil para quien tuviera la intención de actuar, intenciones que podían verse modificadas durante la investigación o por los resultados de esta dentro de un recorrido lineal que, desde la subjetividad inicial (los propósitos de aplicación), pasaba por la intersubjetividad (el proceso etnográfico) para volver a una subjetividad inicial modificada (las acciones de aplicación).

\footnotetext{
3 Migrapiés surge como grupo de trabajo de migración de la Asamblea 15M de Lavapiés

4 Dada la extensión que requeriría tratar como se articulan todos estos significados entre los activistas en Migrapiés, y ya que esto se aleja del objeto principal del texto, me limito a dar un pequeño esbozo sobre estas cuestiones, remitiendo para una mayor profundidad a otro texto donde se desarrolla la cuestión del funcionamiento de Migrapiés, así como la actividad del grupo en sus primeras etapas (Méndez, 2012)
} 
Los resultados de la investigación ayudaron a Migrapiés a descartar una "participación" de mujeres "bangladesíes" y "africanas" en el grupo similar a la que habían seguido los hombres. La sociabilidad de estas, condicionada por determinados roles de género se enfocaba hacia otras mujeres y el espacio privado. Tanto la presión grupal hacia quienes se salían de los roles establecidos, como el propio deseo de organizarse entre ellas para atenuar las desigualdades de poder que muchas sentían actuando conjuntamente con hombres, indicaban la poca viabilidad de pretender que se incorporaran a un grupo donde la mayoría eran varones. Era mejor buscar otras vías apropiadas al contexto observado. Estos resultados llegaban con una reflexión: el objetivo de la investigación y mi posición como miembro de Migrapiés había dirigido mi análisis principalmente a mujeres periféricas a los participantes del grupo y a otros colectivos asociados con este. Esto producía un conocimiento situado que no abarcaba a cualquier mujer "africana" o "bangladesî" en Lavapiés. Los roles de género que condicionaban las relaciones entre hombres y mujeres, sumados a mi condición de "español" y por tanto "ajeno" a la "comunidad" "bangladesî" o "africana", delimitaban mi campo investigativo, dificultándome el acceso a ciertos espacios de mujeres tales como reuniones en ámbitos privados. Esto dirigió mi trabajo a espacios públicos y a mujeres más dispuestas a afrontar la presión social en torno al género, eliminando a su vez otras posibilidades investigativas. A fin de cuentas, el campo de trabajo etnográfico es relacional y estas relaciones, en mi investigación, derivaron tanto de las intenciones de acción como de las posibilidades que mi posición en el campo me ofrecía. Esto indica que si bien es posible establecer distinciones de carácter analítico en torno a subjetividad e intersubjetividad, el propio diseño de la etnografía, anclada en la práctica y lo relacional, implica un entrelazamiento complejo de nuestras propias subjetividades con la investigación.

Esta inclusión de lo subjetivo en lo intersubjetivo invalida planteamientos que aborden la neutralidad o la objetividad ${ }^{5}$ como requisito de investigación. Tenemos aquí dos aspectos a considerar: la relación entre conocimiento y acción y la forma en la que nos relacionamos con las personas en el campo. La parcialidad y posicionalidad del conocimiento indican que la etnografía aporta información válida, pero no produce una verdad objetiva que dé respuesta a lo qué hay que hacer. Es por esto que la etnografía no va a aportar soluciones de facto. Las decisiones sobre posibles acciones van a pasar por las subjetividades posicionadas de quienes estén en disposición de actuar y su consideración de lo que es adecuado a partir del conocimiento parcial obtenido. Además, la pretensión de neutralidad puede llevar a una conceptualización errónea del proceso etnográfico, oscureciendo la doble agencia en la que nos movemos a la hora de hacer etnografía, derivada de compromisos simultáneos con la investigación y con las relaciones cotidianas durante el proceso (Díaz de Rada, 2010). La búsqueda de una metodología que permita abordar el conocimiento lo más rigurosamente posible nos acercará a una relación dialógica y reflexiva en el campo, lo que hace necesario cierto distanciamiento. Pero esto no significa que en la otra vertiente de la actividad, la de la relación con otras personas, tengamos que ser asépticos. A fin de cuentas existe influencia al relacionarnos, queramos o no. Se trata, en definitiva, de disolver una inclinación que nos haga pensar que una etnografía es meramente objetiva y cómo tal nos dicta lo moral a la hora de actuar. O, en el otro lado del mismo argumento, que la objetividad de la investigación necesita de trabajos neutrales donde quien investiga no "tome partido" y acabe apoyando el statu quo (Fals Borda, 1999).

Para ampliar estas dos cuestiones me centraré en cómo desde Migrapiés se aplicaron los resultados de la investigación. Una vez realizada, esta fue devuelta al polo subjetivo (a las intenciones del grupo). En ese momento, surgieron unas cuantas dudas. Por ejemplo, en el caso de mujeres que afirmaban estar de acuerdo con una separación de roles hombre trabajador/mujer cuidadora, ¿hasta qué punto intervenir o qué grado exacto de relativismo ejercer ante lo que diferentes personas en Migrapiés consideraban una opresión patriarcal? Es más, dada la variedad de circunstancias encontradas entre estas mujeres (activistas en diferentes campos, otras veces no; universitarias y personas sin estudios; esposas, solteras, divorciadas; religiosas devotas o ateas convencidas...) y dado que el estudio precisamente concluía los múltiples niveles de identificación que variaban entre ellas, una compleja trama en la que mujeres ligadas por unos aspectos (por ejemplo por la pertenencia a una determinada asociación) estaban separados por otros, ¿cómo pensar en acciones culturalmente válidas para esta variedad? Para parte de estas cuestiones, la etnografía podía servir para pensar, para incluir la reflexión en nuestros actos, pero en toda decisión había una componente subjetiva a la que la etnografía no puede responder, porque no es su función. Si bien la etnografía había permitido acercarse a Migrapiés a un entorno desconocido previamente, era necesario decidir diferentes formas de actuar a partir de esta. Esto indica que en la relación entre conocimiento y acción siempre va a haber un tercer elemento, la subjetividad de quien articula ambas.

Las dudas al actuar estaban condicionadas por cómo se había producido la relación con estas mujeres durante los meses anteriores. Si mi participación en Migrapiés me permitía compartir lo obtenido con el

5 Entendida aquí la objetividad tanto como pretensión de no influencia del bagaje del investigador en la investigación como considerar los resultados como verdad total 
grupo e incluso que este hubiera participado en la investigación, la forma en que estaba diseñada la investigación (volcada hacia Migrapiés) les daba a ellas un papel más secundario en las posibilidades de toma de decisiones. Estas mujeres eran las principales protagonistas de la investigación/aplicación, pero quedaban relegadas principalmente a informantes durante el proceso etnográfico. La linealidad del modelo utilizado hacía que, en todo caso, ellas pudieran ser beneficiarias en el último paso del proceso, una vez terminada la investigación, pero limitaba la posibilidad de colaboración a lo largo de este. Centrándome en obtener conocimiento antes de actuar, y a pesar de mi intención de focalizarme en sus necesidades autodefinidas, había desplazado a estas mujeres tanto de las acciones que se realizaban durante el proceso investigativo como de la posibilidad de tomar decisiones en igualdad de condiciones con los participantes de Migrapiés. Es decir, había desarrollado la intersubjetividad para la obtención de conocimiento pero no tanto para buscar acciones conjuntas con ellas o dialogar de lo que aportaba la investigación mientras se desarrolla$b a$. Dentro de la doble agencia etnográfica, la dirigida a la investigación había estado mucho más presente que aquella que iba hacía las relaciones cotidianas, lo que indica falta de reflexión sobre las posibilidades relacionales que la etnografía brinda.

$\mathrm{Al}$ devolver el proceso intersubjetivo a la parte subjetiva de toma de decisiones, faltaba precisamente la subjetividad de las mujeres. Porque esta investigación se había realizado "por su bien" pero sin contar con ellas en algunos de los aspectos que, como veremos a continuación, puede brindar el dialogo etnográfico. Normal entonces que dentro de la vocación de Migrapiés de actuar "horizontalmente" y en colaboración con las dueñas del problema, el resultado fuera que el grupo no pudiera hacer mucho más que intentar construir relaciones de apoyo con estas mujeres y esperar a que fueran ellas quienes tomaran la iniciativa que les correspondía. El modelo de investigación planteado no queda invalidado por esto, pero sí podemos añadir ciertas reflexiones que permitan ampliarlo para abarcar otras posibilidades en la confluencia entre investigación y acción. Este modelo no tiene por qué ser lineal (planteamiento de problema, investigación, aplicación) sino que la verdadera potencialidad es la de poder pensarse como una espiral que permita plantear modos entrelazados de investigación-acción con mayores posibilidades de desarrollo que la de aportar información a posteriori. Una vez conceptualizada la relación entre subjetividad en la acción e intersubjetividad etnográfica, podemos acercarnos al trabajo de campo como una posibilidad de re-creación de asociaciones que modifican este, donde la etnografía no es la única posibilidad relacional ni el único elemento reflexivo que interviene en el dialogo constante entre los agentes (quien etnografía uno más) en el campo.

\section{3.- Experimentando con la Investigación Acción Participante. Formas de colaboración}

El incremento del trabajo colaborativo y de los debates sobre el apoyo y la defensa de las "comunidades" estudiadas por parte de los antropólogos estaría datado, para Rylko-Bauer, Singer y Van Willigen (2006) en la crisis de la representación de finales del s. XX. Para estos autores habría diferentes formas de conceptualizar la utilidad etnográfica: desde propuestas basadas en la comprensión del ser humano, entendiendo el conocimiento no específico como un valor en sí mismo, a compromisos con una defensa abierta de las "poblaciones subordinadas". En este abanico encontraríamos actividades tales como la denuncia del etnocentrismo, la escritura de artículos exponiendo desigualdades sociales, la promoción del dialogo en diversidad o el uso de la antropología al servicio del "otro" desde la acción directa y la defensa de derechos de grupos específicos. En estos debates se incluyen también las metodologías colaborativas mientras se intenta abandonar una posición de expertos que estudian a los "otros" para abordar arreglos donde los implicados puedan ver sus capacidades potenciadas por la participación en la investigación (Lamphere, 2004). Dentro de la colaboración se plantean cuestiones como los derechos y obligaciones de los participantes, la negociación sobre qué investigar, la forma de analizar los resultados o la importancia que estas investigaciones pueden tener al trabajar con diferentes tipos de organizaciones, como ONG's o grupos "profesionales" (Lamphere, 2004). Lassiter (2005) define la investigación colaborativa como aquella que va más allá del apoyo a la "comunidad", buscando un beneficio mutuo dónde ambas partes son iguales y participan en la investigación con objetivos comunes. Esto implicaría llevar la metáfora del dialogo más allá de la investigación, hacia la escritura conjunta. Para Rappaport (2008) la colaboración afecta a todos los pasos del proceso etnográfico, que deben negociarse con los colaboradores.

Muchas de estas propuestas se basan en la investigación. Otra forma de colaboración sería la investigación acción participante (IAP), desarrollada en los años setenta en Latinoamérica desde el proyecto pedagógico de Freire y Fals Borda, entre otros, y centrada la posibilidad de investigar y aplicar conjuntamente, planteando que la teoría no fundamenta la práctica, sino que puede generarse desde la segunda, y que la teorización debe ser puesta al servicio de un cambio social positivo (Brydon-Miller, Greenwood y Maguire,

6 La horizontalidad en este texto se refiere a la vocación de analizar las relaciones de poder dadas en un entorno concreto para tratar de limitar las posibles desigualdades en estas 
2003). Greenwood (2000) reflexiona sobre la metodología clásica de la observación participante que, en su opinión, privilegia la observación por encima de la participación. En la IAP participación y observación se transformarían en colaboración y reciprocidad dentro de una negociación con los "dueños del problema" donde el etnógrafo/a, se convierte en parte de lo observado, redefiniéndose las relaciones clásicas en el campo dentro de un co-aprendizaje destinado a la acción. Estamos entonces hablando de una forma diferente de conceptualizar la doble agencia, buscando que las relaciones de reciprocidad con los agentes formen parte de aquellas que se dirigen hacia la parte investigativa. Esta forma de entender el trabajo colaborativo puede ayudar a comprender las limitaciones que mostraba en el apartado anterior: la investigación entre mujeres "bangladesíes" y "africanas" había sido dirigida a las dueñas del problema, pero diseñada desde un encargo externo y ejecutada sin contar con ellas, limitando las posibilidades de intervención en lo referente a su participación, alejando investigación de aplicación y jerarquizando las relaciones en el campo entre quienes se hacen cargo del problema y lo investigan y quienes son receptores de la acción.

Pensar desde la IAP puede ser una forma de trabajar esta problemática, pero antes tendríamos que reflexionar sobre si las metodologías colaborativas, sobre todo si se establecen dirigidas a la investigación, puede realmente horizontalizar las relaciones en el campo. ¿Estas metodologías van a funcionar si son implantadas desde el bagaje epistemológico de los antropólogos/as? Para ampliar estas cuestiones recojo otro ejemplo de mi actividad etnográfica. En paralelo a mi TFM realicé una investigación de fotografía participativa con compañeros de Migrapiés. La idea era complementar la investigación principal y, a la vez, generar una exposición que pudiera servir para denunciar las condiciones que sufrían los migrantes "sin papeles" "en Lavapiés. La necesidad de generar una lógica de investigación como paso previo a comenzar a investigar también estaba presente en este trabajo. Pero a mi modo de ver se me habría una oportunidad tanto de profundizar en las posibilidades de aplicación de la etnografía como de experimentar con metodologías participativas, por lo que el proyecto se realizó siguiendo de cerca las nociones de IAP que he descrito. Realizamos varias reuniones iniciales para explicar la investigación donde además de acordar el proceso discutimos sobre las categorías de análisis (tales como la incorporación, el transnacionalismo o los conflictos cotidianos). Si bien estas partían de mis propuestas, fueron debatidas para clarificarlas y adaptarlas a los intereses de los participantes. En esta primera parte, me parecía fundamental acercar todo lo posible a los colaboradores los presupuestos de la investigación etnográfica e introducirles en el proceso de reflexividad. Tras estas reuniones, cada colaborador realizó fotos sobre problemas que hubieran tenido durante su proceso de incorporación al destino migratorio. Luego realicé entrevistas personales donde discutimos sobre las fotografías, centrándonos en los motivos de realización y elección para después enfocar la conversación en base a las categorías consignadas. A partir de este análisis, reflexionamos sobre posibles soluciones a las problemáticas planteadas. Luego trabajamos en grupos de discusión para contrastar las diferentes fotografías realizadas y las impresiones que sobre estas tenían los colaboradores. De todo esto salió tanto una elaboración etnográfica sobre las problemáticas referidas como reflexiones sobre la manera de abordarlas. Finalmente, la exposición constaba de dieciocho fotografías escogidas y las aportaciones del grupo de discusión. Estas imágenes se concebían como textos de reflexión críticos que contaran historias de migrantes enredados en relaciones desiguales de poder a la vez que, mostrando su cotidianeidad, contribuyeran a alejar estereotipaciones y exotizaciones, construcciones sociales que los convierten en "otros" alterizados, elementos extraños dentro de la "sociedad" que les "acoge".

En conjunto, la experiencia fue positiva y el trabajo me ayudó a avanzar en la comprensión de cómo se cristalizaban en mi entorno de estudio cuestiones como la incorporación en el destino migratorio, las redes de apoyo o el "nacionalismo". Sin embargo, siempre vi este trabajo como un fracaso parcial. Me parecía que el proceso había estado demasiado dirigido por mí, lo que restaba, a mi parecer, valor a la metodología participativa que había explorado. Lo que más me preocupaba era el desinterés en la investigación en sí, en sus aspectos más etnográficos o en la composición de la exposición con una perspectiva etnográfica, algo que generalmente, y a pesar de mis quejas, me dejaban a mí. En algún caso llegué a pensar que estaban participando más por hacerme un favor que por otra cosa. Me quedó una reflexión amarga que hacer sobre la IAP: ¿hasta qué punto puede pensarse que una metodología de este tipo y la presencia de los dueños del problema durante la investigación permitirá textos con un grado de expresión autónoma que no se encuentra en las etnografías en solitario (Rose, 2011)? Sin negar las potencialidades que puede llegar a tener este tipo de investigación en trabajos con unas circunstancias diferentes al mío, es necesario reflexionar si bajo el manto de la IAP no se puede llegar a cometer el error de disfrazar relaciones de dominación encubiertas por una apariencia colaborativa horizontal que legitime la voz del etnógrafo. Como subraya Sansi (2016) respecto a la colaboración, que exista un intercambio no implica que este no pueda ser jerárquico. Una última pregunta: ¿hasta qué punto no estamos pecando de etnógrafo-centrismo pretendiendo llevar a todo un grupo de personas hacia el campo de conocimientos del etnógrafo, conocimientos que muchas veces son frutos de años de dedicación?

7 Personas que se encuentran en el estado español sin permiso de residencia 


\section{1.-Conceptualizando lo aplicado de la investigación}

Mi argumento es que si pensamos que la colaboración sólo implica etnografía, corremos el riesgo de deslizarnos a lo que de Sousa Santos (2014) llama pensamiento abisal, en relación con lo que yo acabo de denominar etnógrafo-centrismo. Para de Sousa Santos, el pensamiento abisal produce líneas de división del conocimiento que ocultan determinados saberes, excluidos frente a otras distinciones visibles que están en el lado "bueno" de la línea. Ejemplifica esto a partir del debate entre ciencia, filosofía y teología como saberes dentro de la modernidad que ocultan otras posibilidades de saber, tales como los conocimientos populares o indígenas. A partir del pensamiento abisal, Christiansen (2017) habla de epistemologías depredadoras, aquellas que desde la neutralidad, la universalidad y una "postura cognitiva colonizadora" (p. 287) producen la no existencia epistémica. Mi teoría es que durante la realización de este proyecto de fotografía participativa, mi etnógrafo-centrismo me llevo a conducirme a partir de una forma de operar similar a estas epistemologías depredadoras. Mis inquietudes me dirigieron hacia un pensamiento donde lo principal era la etnografía y la forma de aplicar mi conocimiento, desplazando otros conocimientos a la mera forma de material empírico que recopilar, aunque fuera de manera colaborativa, sin tener en cuenta que mi conocimiento no era el único que existía en el campo y que la confluencia de diferentes saberes puede propiciar que la colaboración no tenga que estar centrada en la investigación.

Con el tiempo me di cuenta de que mi proyecto de fotografía participativa sí fue una investigación colaborativa, aunque no en el sentido que yo esperaba. Digamos que la etnografía no me dejó ver el bosque: mis preocupaciones por hacer las cosas de acuerdo a cómo debía desarrollarse una investigación participativa me impido notar en su momento que lo importante para quienes participaban no era la metodología o un resultado ajustado a los cánones etnográficos, sino la posibilidad de transformación de unas dinámicas que concebían injustas. Actuaron como agentes reflexivos decidiendo participar, en qué intensidad hacerlo y fiscalizando los objetivos. Si en algún caso pudo ser que realmente lo que querían era echarme una mano, sus razones tenían, ya fuera por retribuirme mi actividad en Migrapiés o por lo que ellos estimaran. Precisamente una de las conclusiones de esta investigación demarcaba la importancia para un "sin papeles" de "conocer" el nuevo entorno de incorporación, donde entre otras cosas es importante construir asociaciones con quien les puede ayudar (a conseguir "papeles", con el idioma, a encontrar trabajo...) Estas relaciones se enredan en dinámicas complejas que van más allá de la instrumentalización hacia relaciones intensas de afecto y amistad. ¿Por qué yo iba a ser diferente? Mi reflexión sobre la intersubjetividad etnográfica se quedó a medias y me impidió ver que la colaboración había consistido en algo que se había escapado de mis prejuicios, que era otra cosa que se establecía en los parámetros de los participantes en dialogo con los míos; yendo más allá de la etnografía. Mi concepción de cómo hacer una investigación colaborativa derivó en unos parámetros epistemológicos que dejaban fuera otras formas de adquisición y uso del conocimiento que, si bien se desarrollaban en paralelo a la etnografía, no tenían por qué subsumirse a esta. No quiero decir con esto que, en determinados casos no pueda haber una elaboración conjunta de la investigación en todas sus etapas, sino que esto sólo abarca una forma de praxis que no tiene por qué incluir otras. No tener en cuenta la amplitud de posibilidades del proceso dialógico puede llevar a una visión centrada en la colaboración etnográfica que corre el riesgo de deslizarse a lo que Graeber (2009) llama vanguardismo: operar como intelectual que aspira a poder "conducir a las masas en un camino verdaderamente revolucionario" (p. 108) en vez de buscar articulaciones que transiten por formas de operar nuevas y alejadas de alienaciones que refuercen en el trabajo etnográfico las relaciones de poder desiguales preestablecidas.

Considero que mi problema de etnógrafo-centrismo fue producto de una visión incorrecta de lo que significa hacer antropología aplicada, derivada de una dicotomía ampliamente extendida en la investigación social entre hacer investigación aplicada y hacer investigación académica (Uribe Oyarbide, 2015). Esta es una cuestión asociada prácticamente a los inicios de la antropología y a la justificación de la existencia de esta por las posibilidades que podía tener para la "mejora de la sociedad" (RylkoロBauer et al., 2006). La cuestión sería si es factible hablar de un campo específico de antropología aplicada dentro de la disciplina y qué caracterizaría a esta. Foster (1997) plantea la posibilidad de que la peculiaridad de lo aplicado se base en la existencia de un encargante, y que la primera fase del desarrollo pase por alejarse de las lógicas de este, tal y como yo planteaba respecto a Migrapiés. Sin embargo, si consideramos que el encargante puede ser el mismo etnógrafo y sus inquietudes, esto no difiere de cualquier etnografía en la necesidad de esbozar un marco teórico-metodológico de partida desde el que comenzar a ejercer reflexividad sobre las categorías que guiarán la investigación. Si la antropología aplicada parte de una metodología común a cualquier etnografía, la distinción de un campo específico de aplicación podría abordarse desde el objetivo de producir cambios sociales en los entornos investigados (Foster, 1997). Sin embargo esta conceptualización también entraña ciertas problemáticas sobre qué es hacer observación participante y qué posibilidades relacionales conlleva la intersubjetividad etnográfica. Para Uribe Oyarbide (2015, citando a Peacock) estas 
posibilidades pueden quedar minusvaloradas cuando distinguimos entre trabajos académicos y aplicados, la aplicación es inevitable, incluso en la investigación más erudita: "la antropología ya es aplicada porque se ve envuelta en lo grupos humanos a través de la participación observativa. En el trabajo de campo, el antropólogo se enfrenta a cuestiones éticas, debe resolver tareas prácticas y, le guste o no le guste, todo esto afecta a él y al grupo".

El diálogo en el campo produciría por necesidad una intervención, ya que las acciones del investigador son la forma de realizar la investigación (Lassiter, 2005). Sillitoe (2007) afirma que la idea de aplicar la antropología sería un contrasentido, una paradoja: no es posible aplicar de manera unidireccional una supuesta teoría general antropológica, sino que la teoría se genera de los actos. Es decir, nos adentramos en una primera dimensión de la praxis etnográfica: la teoría y la práctica etnográfica no se pueden dar disociadas, el requisito de intersubjetividad de la investigación obliga a relacionarse en el campo. Sólo desde una visión reduccionista de lo que es el trabajo etnográfico, podemos separar entre lo "académico" y lo "aplicado". Entonces pasamos de pensar en si hacemos investigación aplicada a pensar ¿cómo aplicamos?, de qué modo estamos en el campo, engarzando los presupuestos teórico-metodológicos que condicionan nuestras relaciones con las acciones que realizamos al investigar. La aplicación del proceso etnográfico, enredada en los debates que he revisado, se extiende en diferentes posibilidades que hacen de la cuestión un asunto de futuros potenciales.

Si consideramos la praxis como la imbricación de pensamiento y acción (Álvarez Barragán y Alvarado Castro, 2016), podríamos pensar que la etnografía es una doble praxis anclada en la doble agencia que desarrollamos en el campo. Esta doble agencia podemos abordarla desde la figura de la doble hélice, dos espirales desarrollándose en paralelo a partir de un mismo eje, de manera que en su entrelazamiento forman una única figura compleja. El primero de estos hilos es el que se refiere al trabajo teórico-práctico etnográfico, la necesidad de relacionarse para construir el entorno de trabajo y llevar cabo la investigación. El segundo deriva de relacionarse con las personas en el campo y la posibilidad de tejer objetivos comunes, dejando de ser el proceso etnográfico lo fundamental para ser un conocimiento más entre otros que aportar a la reflexión-acción. Así se produce un enrollamiento donde el hilo objetivos de investigación-intersubjetividad-conocimiento se despliega en paralelo al hilo objetivos de transformación-intersubjetividad-acción. La reflexividad adquiere aquí un doble sentido: el referido a la necesidad etnográfica y el que se presupone de personas que reflexionan sobre sus acciones para conseguir objetivos.

El error al conceptualizar tanto qué es aplicar una investigación como las consecuencias que implica la doble praxis del proceso etnográfico me llevó a mi descontento con los resultados de la investigación de fotografía participativa. La mirada etnográfico-céntrica me ocultó como se estaba produciendo realmente la colaboración con los participantes en el proyecto. Enfatizar la aplicación como algo particular, una diferencia dentro de una disciplina más amplia, encaminada a generar un informe de carácter etnográfico para su posterior aplicación, me impedía ver que la etnografía es aplicada por necesidad. Esto oscurecía las posibilidades que puede brindar la doble praxis que acabo de describir en cuanto a investigación y relación con las personas en el campo, dirigiendo mis esfuerzos hacia la etnografía como forma principal de colaboración y aplicación. La reflexión posterior me hace sostener que la etnografía no tiene por qué plantearse como núcleo central de la colaboración. Esta posibilidad se debe barajar dentro de un mayor abanico de posibilidades donde el eje principal es la intención de establecer relaciones horizontales en el campo dentro de acuerdos que partan del encuentro entre todos los participantes y que recojan las potencialidades de estos en cuanto a sus saberes, tratando de evitar el considerar a los sujetos únicamente como fuentes empíricas (Freire, 1998). Se trata de acordar con los presentes en el campo su participación en todo lo relacionado con la relación producida por nuestra presencia. De esa manera podremos tanto desdibujar la diferencia entre los que producen conocimiento y quienes lo utilizan, como la dicotomía entre conocimiento formal y práctico para abordar saberes y acciones contextuales y relacionales (Anderson y Herr, 2007)

Planteo entonces el uso de metodologías que no sólo trabajen los problemas de la creación de otredad o de la representación, sino la forma de colaborar con las personas investigadas. Mi investigación durante el TFM puede aportar reflexiones en este sentido. Mi posición en el campo hacía que mis intereses investigativos se entrelazaran fácilmente con los intereses de Migrapiés, dirigiéndome en la tensión entre lo que me pedía la etnografía y lo que me pedía Migrapiés. Esto contribuyo a combinar etnografía y acciones, buscando la utilidad para quienes transitan los entornos de estudio. Pero si bien esto muestra la compatibilidad del conocimiento etnográfico con la búsqueda de objetivos de transformación concretos, a la luz de los visto hasta aquí podemos pensar que el énfasis en obtener conocimiento antes de aplicarlo o el limitar las posibilidades de colaboración durante la investigación nos puede conducir a un modelo lineal (investigar, luego actuar) que no recoge todas las posibilidades y complejidades de la doble praxis planteada, frenando otras posibilidades de acción colaborativa. En el siguiente apartado aportaré ejemplos de esta doble praxis en espiral que permita ligar de maneras diferentes acción e investigación. 


\section{4.-Otras formas de colaboración. Experimentación y modos de estar en el campo}

Tras lo desarrollado en los apartados anteriores comencé mi investigación de doctorado, también encaminada a la aplicación del conocimiento etnográfico en el entorno de estudio a partir de los intereses de Migrapiés. Mi idea era formar un grupo que pudiera implementar acciones a partir de los resultados que fuera arrojando la investigación. Lo que me movía a plantear esto era que me parecía que la investigación previa para el TFM no había terminado de aplicarse en Migrapiés, un grupo marcado por muchos objetivos y por una urgencia cotidiana que dificultaba un trabajo más pausado en el sentido que yo quería darle a la investigación y su aplicación. De esta manera, podía separarse la investigación de la labor de Migrapiés, para que el grupo pudiera participar de los resultados, pero desde el trabajo realizado por las personas interesadas en el tema. En este momento, mi objeto de estudio había cambiado: de la incorporación de mujeres "bangladesíes" y "africanas" hacia procesos de colectividad mediados por la migración y su relación con los roles de género, lo que implicaba una modificación de los entornos de investigación y convertía a Migrapiés no sólo en el encargante, sino también en parte de lo estudiado.

Transcurrido un año de investigación, cada vez estaba más seguro que mi idea de aplicación iba a quedar abandonada. Había dos razones principales para ello. La dedicación a las cuestiones más "académicas" de mi investigación y la participación en Migrapiés no me dejaban tiempo para mucho más. Por otro lado, me parecía que no tenía todavía conclusiones lo suficientemente elaboradas que aportar. A veces, durante este tiempo, me embargaba cierto agobio por no estar cumpliendo ni en un sentido ni en otro. La investigación me quitaba tiempo de "militancia" y viceversa. Algo que para mí era fundamental, utilizar mi trabajo dentro de acciones de cambio social, parecía aparcado por mis intereses "académicos". Sin embargo, considero que esta sensación de fracaso estaba originada por lo descrito antes: una conceptualización errónea sobre lo que yo pensaba que tenía que ser un proyecto de antropología aplicada derivada de la falta de atención al desarrollo intersubjetivo durante el trabajo de campo y a las implicaciones de la praxis etnográfica. Pues en un momento dado me di cuenta de que no había hecho lo que tenía pensado hacer porque estaba ocupado haciendo otras cosas. Y estas cosas tenían mucho más que ver con esta praxis de lo que yo pensaba en un principio. Para explicar esta cuestión, nada mejor que describir algunas de estas cosas que hacía mientras pensaba que no hacía lo que debía.

\section{1.- Colaborar y compartir durante la investigación}

Durante mi primer año de doctorado, Vanesa Camarda, compañera de Migrapiés y profesora de Teatro del Oprimido (TO), me planteó una colaboración para una obra de teatro-periódico que estaba montando para uno de sus cursos. El TO es una propuesta teatral para promover el cambio social desarrollada por Augusto Boal. Su técnica más característica es el teatro-foro, que consiste en plantear un problema (una opresión) en una representación teatral y después realizar un foro donde el público trata de aportar soluciones sustituyendo a uno de los actores para poner en práctica sus propuestas, tratando que el pensamiento sea indisoluble de la misma acción. Se busca transformar al espectador en especta-actor, dejar de lado una recepción pasiva para sustituirla por acción transformadora, un proceso de intersubjetividad in-corporada donde se produce la praxis. En la obra en cuestión queríamos mostrar lo estructural de las condiciones de los migrantes "sin papeles" al llegar a España y, a la vez, experimentar formas de denuncia diferentes a las que ya realizábamos en Migrapiés sobre estos temas. Por aquel entonces mis preocupaciones teóricas estaban dirigidas a Latour (2008) y su formulación de lo colectivo: mundos comunes basados en la relacionalidad. Me pareció que precisamente este concepto tenía potencial para intentar otras formas de pensar las pertenencias. Esto se complementaba con otras de mis lecturas habituales por entonces: el trabajo de Massey $(2005 ; 2012)$ sobre el sentido global del lugar y las políticas de responsabilidad también podían aportar formas de construir imágenes de lo colectivo que fueran más allá del origen o la "clase". Un último punto a incorporar era el de concebir lo estructural de una manera dinámica, como una serie de elementos de amplia difusión que se transmiten y concretan contextualmente en diferentes particularidades.

Con estas herramientas adopte un rol de colaborador-asesor en el planteamiento inicial y, obviamente, Vanesa y su alumnado no me hicieron caso en todo, sino que adoptaron mis propuestas dentro de un posicionamiento propio de denuncia en el montaje final. La obra consistía en tres actos. El primero, partiendo de audios y noticias periodísticas, planteaba elementos estructurales: las muertes de migrantes en el Mediterráneo o la construcción de un nosotros, la "españolidad", y un ellos, "los de fuera". La segunda parte mostraba la individualidad, historias de migrantes "atrapados" en esos condicionantes. En el tercer acto se daba al público tarjetas de personas asociadas por diferentes elementos (familiares, económicos, laborales...) para luego, con una cinta elástica, ir creando una red asociativa que planteara otras forma de pensar el mundo común, pasando luego al debate. He de decir que la obra no cumplió los objetivos planteados en su totalidad. Por ejemplo, no quedaba plasmada del todo la idea de Latour de asociación y la simetría que implica 
en torno a humanos y no-humanos, con frecuentes alusiones en los debates a una dicotomía entre redes de personas y redes económicas. Tampoco quedamos satisfechos respecto a nuestra intención de "hacer pensar de otra manera". Asistí varias veces a las representaciones y el debate se atascaba en planteamientos sobre multiculturalidad e identidad que no abordaban la posibilidad de plantear otras posibles colectividades más allá del origen o la clase. Sin embargo, la obra cumplía su función de denuncia como objetivo principal planteado por la compañía y los problemas en su concreción nos permitieron reflexionar sobre futuras formas de reformularla para cumplir sus objetivos. Además, la planificación de la obra, al igual que muchas conversaciones posteriores con Vanesa u otros compañeros sobre mi investigación y Migrapiés, sirvió para poner a prueba mis planteamientos teóricos, reflexionar sobre ellos y observar sus fallos. Entre otras cosas, esta colaboración me permitió pensar en qué significaba la praxis y cómo podía aplicarla a mi investigación. También para repasar mi propia subjetividad sobre cuestiones como la migración, lo colectivo y las formas de alcanzar determinados objetivos. En todo caso, se estableció una colaboración que fue más allá de la escritura de un texto etnográfico hacía un diálogo con sujetos reflexivos que marcaron las condiciones de colaboración. Y esta colaboración no sólo arrojo resultados en el ámbito de la acción, sino también en la producción etnográfica.

A lo largo de estos años de investigación también he escrito textos que, si bien tenían relación con mi investigación, no tenían el formato ni la intención presupuesta para un texto académico, sino que estaban escritos con vocación de denuncia. Esos textos han sido para mí posibilidades de experimentar y desarrollar diferentes conceptos, una forma de manipularlos y observar cómo resistían mis propios cuestionamientos y los de otros, permitiéndome avanzar en la formulación teórica. También he seguido el camino contrario. Considerando que aquellos textos dirigidos hacia mi actividad académica también tenían potencial para brindar reflexiones válidas a quienes no participan de la academia, he difundido estos por diferentes medios, desde la comunicación personal a su publicación en redes sociales. Esto me ha permitido una retroalimentación de cara a mis avances en la investigación. En un principio, estas cuestiones las consideraba parte de mi militancia más que relacionadas con la propia investigación: Devoluciones que mi labor antropológica podía realizar a mis intereses transformadores. Luego me di cuenta de que, casi sin quererlo, estaba propiciando la posibilidad de que quienes aparecían en mis textos pudieran discutirlos conmigo y, si mi trabajo les valía, aprovecharse de ellos (Stavenhagen, 1992). Sin demasiada sistematización, estaba realizando lo que Fals Borda (1999) llama restitución, proceso que pasa por una modificación de las costumbres de representación para adecuar diferencialmente estas representaciones a diferentes colectivos. La difusión de estos textos no obedecía a una aplicación lineal de la investigación, sino que se enmarca en un funcionamiento en espiral donde las acciones sobre el campo propiciadas por la etnografía pueden ser devueltas a la propia investigación.

\section{2.- Una crisis en Migrapiés. La etnografía en el diálogo de saberes}

Durante el invierno de 2016, Migrapiés sufrió una disminución de integrantes. El crecimiento del grupo en años anteriores originó la diversificación de intereses hacia diferentes proyectos surgidos del propio grupo de manera que la duplicación o triplicación de esfuerzos llegó a ser tal que muchos tuvieron que elegir. A esto se sumaron varios éxitos a la hora de conseguir el permiso de residencia de "sin papeles" del grupo, lo que les desplazaba hacia otra etapa: una vez obtenidos los "papeles", la necesidad de mandar dinero a "casa" combinada con la dificultad para conseguir trabajo fuera de determinados nichos laborales confluía en horarios de trabajo maratonianos que dejaban poco tiempo para el grupo. Casi morir de éxito, se podría decir. Para primavera existía cierta preocupación por esta disminución de fuerzas, decidiéndose replantear las actividades del grupo y la forma de "sumar fuerzas". En los debates que siguieron, participé como miembro del colectivo, no como un etnógrafo asesor (muchas veces me veo en la obligación de recordar mi investigación, no se les vaya a olvidar). Sin embargo, en mis opiniones y recomendaciones pesaba mucho todo aquello que la etnografía estaba aportando. Por ejemplo, a la hora de abordar la tensión que existía en Migrapiés entre la forma de "participación" que he descrito anteriormente, basada en el apoyo mutuo y la "lucha contra el sistema" y una "participación" de algunos "sin papeles" encaminada a aliviar las necesidades urgentes que la migración originaba en ellos, tales como conseguir regularizar la estancia en el estado español. La reflexión sobre las lógicas que regían la participación y la pertenencia a Migrapiés me permitieron realizar aportaciones al colectivo que, como en el caso de la obra de teatro periódico, no fueron aceptadas como ley, sino que fueron sometidas a debate, rechazadas o reformuladas en un entorno dialógico donde todos éramos "expertos" en Migrapiés, aunque la mochila que cada uno portaba era diferente. De este diálogo salieron una serie de acciones que ayudaron a que la participación volviera a incrementarse desde la primavera. Esto, a su vez, me permitió examinar mis conceptos y mis conclusiones mientras el entorno de investigación era cambiado en cierta medida por el dialogo entre etnografía y otros conocimientos, lo que me aportaba nuevas posibilidades de investigación. Esto se producía dentro de una colaboración 
donde la etnografía era un factor más entre todas las cosas que actuaban, pero no lo único.

Mis entrevistas con participantes de Migrapiés aparecen llenas de reflexiones conjuntas propiciadas tanto por las preguntas de la entrevista como por la cotidianeidad compartida. Y también de propuestas para llevar al grupo e incluso de la adopción de categorías que yo estoy usando en la investigación:

"Pedro: Porque claro, aquí estamos en general los que nos movemos como activistas, uso tu nomenclatura (ríe)... bueno, sí, yo creo que sí... yo creo que a los activistas sí... Yo he sido activista toda mi vida y claro eso no lo voy a soltar así por las buenas. Y cuando me encuentro con otros activistas me encuentro muy bien" Entrevista con participante de Migrapiés

"Moustapha: yo creo que lo que más nos ha fallado es los comedores.

Autor: antes los hacíamos todas las semanas

Moustapha: la gente siempre van a hablar de cuando vas a hacer las cosas. Este va a cocinar, la gente va a venir, tú cuando vienes, ayudando... esas cosas, sabes, tenemos que volver un poco a hacer las fiestas, a hacer los comedores...también a lo de los flyers... los bares, esas cosas también. Hablar con la gente, escuchar a gente, esas cosas, tenemos que hacer, hay que hacer el intento de hacerlo.... como seguimos siendo Migra, sí, podemos volver a hacerlo también" Entrevista con participante de Migrapiés

Estos diálogos entrelazan fluidamente las intenciones etnográficas con las de acción, dándose además dentro de un intercambio de pareceres y conocimientos donde lo que más nos interesa a todos es el desarrollo de Migrapiés. El dialogo que se establece en el campo, ese que es susceptible de aportar información a una etnografía, puede ser el mismo que nos dirige hacia la colaboración con agentes reflexivos que negocian la colaboración. La intersubjetividad como actitud metodológica puede concretarse en colaboraciones de diferente tipo. No pienso que esto tenga que realizarse en contacto con personas que tengan habilidades parecidas al etnógrafo, lo que Holmes y Marcus (2008) han llamado para-sitios. La cuestión es que todo el mundo es "experto" en algo, generalmente en sus vidas, y que si no anteponemos la etnografía por encima de otros saberes, la colaboración puede establecerse en parámetros contextualizados que permitan el dialogo entre los participantes. Que la colaboración no se dé centrada en la investigación, o que el resultado no sea un texto bajo estándares etnográficos, no significa que no hagamos etnografía. Sólo que la hacemos en conjunto con otras cosas. Esto tampoco es nuevo dentro del desarrollo de la antropología. Así, Menzies (2004) recoge los beneficios que otras actividades paralelas a la investigación pueden tener en los entornos estudiados a la vez que alerta del problema de fetichizar la escritura como resultado primario de los esfuerzos investigativos. Y Lassiter (2005) ha mostrado como es posible conciliar una colaboración en la que diferentes partes tengan diferentes objetivos de manera haya beneficios para ambas partes. Esto pasa por subrayar que el conocimiento "nativo" no es algo que deba relegarse a material útil para el desarrollo etnográfico, sino que el compromiso con el pluralismo cultural pasa por poner este conocimiento al mismo nivel que el saber etnográfico a la hora de construir un conocimiento aplicado, un praxis de vocación horizontal (Harrison, 1991).

\section{3.- Etnografía experimental y militancia}

Todo esto me lleva a conceptualizar la colaboración a partir de la experimentación. Marcus describe la existencia de una determinada estética: una forma de imaginar y actuar en el campo que llama malinowskiana y que concibe al etnógrafo en solitario cruzando límites culturales mientras investiga en determinadas "comunidades" (Marcus, 2010). Frente a esto, Marcus argumenta la necesidad de pensar en nuevas formas de etnografía que, desde la relacionalidad del etnógrafo con diferentes agentes la encaminen hacia una colaboración reflexiva donde la estética malinowskiana sea sustituida por el encuentro con quienes participan en el entorno de estudio. Este impulso podría cambiar el modo individualista de hacer etnografía, dirigiéndola hacia formas de colaboración "explicitas pero ambiguas" (Marcus, 2012: 433) que reexaminen la observación participante y permitan alcanzar una potencialidad colaborativa presente en la tradición antropológica pero, en su opinión, largamente reprimida. Esto pone en primer plano la experimentación: el proceso etnográfico, además de reflexivo, se vuelve transitivo y recursivo dentro de una naturaleza colectiva y en colaboración, que requiere no sólo documentación (en diarios y notas de campo, por ejemplo, convirtiéndose éstos en una monografía), sino también formas de proposición, demostración y acceso de públicos y lectores sobre la marcha. (Marcus, 2012: 473, énfasis mío).

La experimentación buscaría que la complicidad generada desborde el dialogo etnográfico desde la posibilidad de perseguir objetivos comunes (Rappaport, 2008). Esto genera una nueva estética, una forma diferente de relación con el campo donde la mediación o la intervención desplazan a la descripción (Marcus, 2010), originando valiosas reflexiones y formas de hacer a la hora de pensar en la investigación 
y sus aplicaciones. Entonces, podemos pensar la etnografía como una práctica de sociabilidad más que como una forma de representación (Sánchez Criado y Estalella, 2016), a partir de una lógica performativa y colaborativa para la creación de espacios públicos (Marrero Guillamón, 2016). Recogiendo las palabras de Wacquant, Juris (2007.) critica la tendencia a ver el mundo como una serie de significaciones que interpretar, en vez de una serie de problemas sobre los que actuar, alegando por la implicación como forma de acceso a la comprensión de lo social. Es en este compromiso donde emerge la etnografía militante a partir del dialogo intersubjetivo, de la posibilidad de hacer y reflexionar conjuntamente con determinados propósitos. Es decir, crear afinidad, compartir y articularse en torno a lo común como forma de crear relaciones de apoyo y solidaridad (Routledge, 2009), una colaboración entendida en un sentido amplio y abierto que pueda maximizar las habilidades de los participantes dentro de sus respectivas capacidades.

La colaboración experimental remite a mi planteamiento de la doble praxis, producida en la implicación en procesos específicos de acción social, donde el conocer se concibe como una herramienta dentro de la búsqueda de reciprocidad entre los intervinientes (Rahman y Fals Borda, 1992). Lo dialógico se convierte en un objetivo político combinando la posibilidad de rigor analítico con una conversación que produzca "un proceso de aprendizaje mutuo y [cambie] la propia naturaleza de la actividad" (Stavenhagen, 1992: 46). Con ello se plantea una etnografía militante, comprometida con el dialogo más allá de la etnografía, de manera que la investigación pueda ayudar a la reflexión sobre la acción de todos los participantes. Podemos hablar entonces de modos de estar en el campo que propicien la intersección entre investigación social y militancia a partir de objetivos dialogados dentro de procesos de transformación social (Juris, 2007).

\section{5.- A modo de cierre. Una reflexión sobre la moralidad}

En este texto he planteado la posibilidad de entrelazar intenciones de intervención y etnografía, subrayando que una cosa no quita a la otra, que es posible hacer investigación comprometida y a la vez trabajar con una metodología intersubjetiva que mantenga el rigor en la obtención de conocimiento. Esto pasa por deconstruir la tradicional separación entre antropología aplicada y antropología académica para pensar que siempre estamos aplicando al investigar y que, en todo caso, hablaremos de diferentes modos de estar en el campo. La etnografía conlleva una doble praxis que entrelaza intereses investigativos y acciones relacionales, lo que nos permite diferentes formas de colaboración descentradas del proceso de investigación. Esto nos puede permitir alejarnos de pensamientos etnógrafo-céntricos, valorar las posibilidades del encuentro de diferentes conocimientos y construir compromisos que nos lleven hacia modelos de investigación-acción en espiral, etnografías experimentales y militantes donde acordar compromisos que permitan estéticas de trabajo tendentes a la horizontalidad.

Un último aspecto que tratar aquí es la cuestión de la moralidad. La crítica realizada a visiones asépticas o neutrales de la investigación no debe entenderse como un todo vale en lo referente a la moralidad en el campo. Al contrario, se trata de incluir esta en el proceso intersubjetivo y reflexivo, tanto en lo que compete a la investigación como a la acción. Que nuestras acciones en el campo tienen consecuencias se deriva de que somos personas relacionándonos con otras, haciéndose necesaria una constante reflexión sobre cómo estas acciones afectan a los demás. La doble agencia en la que entrelazar investigación y acción origina una doble moralidad (Díaz de Rada, 2010): la orientada hacia el campo y el trato con las personas en él y la que obliga al rigor y la honestidad en la investigación. Pensar en términos de doble agencia puede proporcionar una base moral para una metodología colaborativa y experimental, que se muestra, de entrada, y más allá de la implicación de quien realiza la etnografía, en lo que Díaz de Rada (ibíd.) llama bagatelas de la moralidad ordinaria. Acciones tales como esforzarse por comunicarse en el idioma de los agentes, colaborar con ellos o comprometerse con la diversidad, además de dirigirse a cuidar a las personas en nuestros entornos de investigación, nos van a permitir diferentes formas relacionales en el campo y, como forma intersubjetiva, obtener conocimiento etnográfico de estas.

Además, la doble agencia permite reflexionar sobre cómo se entrelaza la moralidad posicionada de cada uno con la etnografía si entendemos la primera como un proceso cultural susceptible de ser modificado durante la investigación (Díaz de Rada, 2010). La intersubjetividad modificará nuestra visión del campo, tanto en la labor etnográfica como en el trato con personas. Así, nuestros actos en el campo no tienen que ver con la asepsia ni con la neutralidad, sino con un posicionamiento sujeto a restricciones reflexivas y cambiante en el contacto con otras personas, mientras se camina en la tensión que originan las agencias como investigador y cómo persona posicionada en determinados entornos, con las obligaciones y acciones que cada una conlleva. Por ello el conocimiento etnográfico puede no aparecer tras la investigación para de forma unidireccional aportar información. Tampoco el antropólogo tiene por qué realizar actos no-etnográficos para retribuir la ayuda de los informantes o como aspecto secundario de la investigación etnográfica. Se trata más de una actitud metodológica-moral que incluya acción e investigación en un constante ir y venir entre ambos. La doble praxis permite así un modelo en espiral que permite caminar por la investigación 
mientras aporta posibilidades de acción en diferentes ámbitos que a su vez nos harán avanzar en nuestras investigaciones. Intersubjetividad y subjetividad desarrollándose a la vez como las dos patas de la doble agencia en la que el etnógrafo/a está inmerso.

\section{Bibliográfía}

Álvarez Barragán, G., \& Alvarado Castro, I. (2016). La praxis teatral como proceso político. Una aproximación antropológica. Ankulegi. Revista De Antropología Social, 19, 97-110. Recuperado de https://dialnet.unirioja.es/descarga/articulo/5647833.pdf

Anderson, G., Herr, K. (2007). El docente investigador: la investigación-acción como una forma válida de generación de conocimientos. En I. Sverdlick (ed.) La investigación educativa. Una herramienta de conocimiento y acción (pp. 47-69). Buenos Aires: Nov. Educativas.

Brydon-Miller, M., Greenwood, D. \& Maguire, P. (2003). Why action research? Action Research, 1(1), 9-28. doi: 10.1177/14767503030011002

Cañedo Rodríguez, M. (2011). Discursos vecinales sobre la inseguridad ciudadana y políticas de rehabilitación urbanística: el caso de los antiguos vecinos y la ARI-Lavapiés (Madrid) desde una perspectiva antropológica. Scripta Nova: Revista Electrónica De Geografía Y Ciencias Sociales, XV(385).

Christiansen, M. (2017). Epistemología depredadora y paz violenta. Consideraciones filosóficas sobre la construcción de una justicia cognitiva. International and Multidisciplinary Journal of Social Sciences, 6(3), 281-306. doi: 10.17583/rimcis.2017.2992

De Sousa Santos, B. (2014). Más allá del pensamiento abismal: de las líneas globales a una ecología de saberes. En B. de Sousa Santos \& M. Meneses (eds.), Epistemologías del sur. Perspectivas (pp. 21-66). Madrid: Akal.

Díaz de Rada, A. (2010). Bagatelas de la moralidad ordinaria. Los anclajes morales de la investigación etnográfica". En M. del Olmo (comp.), Dilemas éticos en antropología. Las entretelas del trabajo de campo etnográfico (pp. 57-77). Madrid: Trotta.

Díaz de Rada, A. (2012). Cultura, antropología y otras tonterías. Madrid: Trotta.

Dirección General de Inmigración (2009). II plan Madrid de convivencia social e intercultural. Madrid: Ayuntamiento de Madrid.

Fals Borda, O. (1999). Orígenes universales y retos actuales de la IAP (investigación acción participativa). Peripecias, 110,1-14. Recuperado de http://xa.yimg.com/kq/groups/19326480/213823660/name/ FALSBORDA.pdf

Foster, G. M. (1997). Un Modelo de Antropología Aplicada. En P.Guerrero (comp.) Antropología aplicada (pp. 87-104). Quito: Ediciones UPS.

Freire, P. (1998). Educación y participación comunitaria. Revista Tarea, 41, 29-33. Recuperado de http:// acervo.paulofreire.org:8080/jspui/bitstream/7891/1137/1/FPF_OPF_01_0004.pdf

Glick Schiller, N. (2007). Beyond the nation-state and its units of analysis: Towards a new research agenda for migration studies. (Working Papers, 33). Bielefed: Center on Migration, Citizenship and Development

Graeber, D. (2009). Anarchism, academia, and the avant-garde. En R. Amster; A. de León, et al (eds.), Contemporary Anarchist Studies. An introductory anthology of anarchy in the academy (pp. 103-112). New York: Routledge.

Greenwood, D. J. (2000). De la observación a la investigación-acción participativa: una visión crítica de las prácticas antropológicas. Revista de Antropología Social, 9, 27-49. Recuperado de http://www. redalyc.org/html/838/83800903/

Harrison, F. (1991). Decolonizing anthropology. Moving further toward an anthropology for liberation. Virginia: American Anthropological Association. doi: 10.1111/an.1992.33.3.24/

Holmes, D. R.; Marcus, George E. (2008). Collaboration today and the re-imagination of the classic scene of fieldwork encounter. Collaborative Anthropologies, 1(1), 81-101.

Juris, J. (2007). Practicing militant ethnography with the movement for global resistance in Barcelona. En S.Shukaitis \& D. Graeber (eds.), Constituent imagination: Militant investigations, collective theorization (pp. 164-176). Oakland: AK Press Oakland.

Lamphere, L. (2004)."'The convergence of applied, practicing, and public anthropology in the 21st century. Human Organization, 63(4), 431-443. doi: 10.17730/humo.63.4.y14pe24v7ekyklyp 
Lassiter, L. E. (2005). Collaborative ethnography and public anthropology. Current Anthropology, 46(1), 83-106. doi: 10.1086/425658

Latour, B. (2008). Reensamblar lo social. Buenos Aires: Manantial.

Marcus, G. E. (2010). Contemporary fieldwork aesthetics in art and anthropology: experiments in collaboration and intervention. Visual Anthropology, 23(4), 263-277. doi: 10.1080/08949468.2010.484988

Marcus, G. E. (2012). "The legacies of writing culture and the near future of the ethnographic form: a sketch". Cultural Anthropology, 27(3), 427-445. doi: 10.1111/j.1548-1360.2012.01152.x

Marrero Guillamón, I. (2016). Objetos textuales y dispositivos colaborativos: de la etnografía como plataforma pública. Revista De Dialectología Y Tradiciones Populares, 71(1), 31-38. doi: 10.3989/ rdtp.2016.01.001.02

Massey, D. (2005). Lugar, identidad y geografías de la responsabilidad en un mundo en proceso de globalización. Treballs De La Societat Catalana De Geografía, 57, 77-84.

Massey, D. (2012). "Un sentido global del lugar". En A. Albet \& N. Benach (eds.), Doreen Massey: un sentido global del lugar (pp. 112-129). Barcelona: Icaría.

Méndez, J. R. (2012). Solidaridad y ayuda mutua: El Grupo de Migración y Convivencia de la Asamblea Popular de Lavapiés. Teknokultura, 9(2), 41-60. Recuperado de https://dialnet.unirioja.es/descarga/articulo/4165476.pdf

Menzies, C. R. (2004). Putting words into action: Negotiating collaborative research in Gitxaala. Canadian Journal of Native Education, 28(1/2), 15. Recuperado de https://search.proquest.com/openview/ 47c255d121aaa7e43f46a04c27d58d95/1?pq-origsite=gscholar\&cbl=30037

Portes, A. \& Böröcz, J. (1989). Contemporary immigration: Theoretical perspectives on its determinants and modes of incorporation. International Migration Review, 1989, 606-630. doi:10.2307/2546431

Rahman, A. \& Fals Borda, O. (1992). La situación actual y las perspectivas de la investigación-acción participativa en el mundo. En M. Salazar (ed.), La investigación acción participativa. Inicios y desarrollos (pp. 205-233). Madrid: Popular.

Rappaport, J. (2008). "Beyond participant observation: Collaborative ethnography as theoretical innovation. Collaborative Anthropologies, 1(1), 1-31. Recuperado de https://muse.jhu.edu/article/367015/ summary

Rose, G. (2011). Visual methodologies: An introduction to researching with visual materials. Glasgow: Sage.

Routledge, P. (2009). Toward a relational ethics of struggle. En R. Amster, A. de León; et al (eds.), Contemporary anarchist studies (pp. 82-92). New York: Routledge.

Rylko $\square$ Bauer, B., Singer, M. \& Willigen, J. (2006). Reclaiming applied anthropology: Its past, present, and future. American Anthropologist, 108(1), 178-190. doi: 10.1525/aa.2006.108.1.178

Sánchez Criado, T. \& Estalella, A. (2016). Antropocefa: un kit para las colaboraciones experimentales en la práctica etnográfica. Cuadernos de Arte y Antropología, 5(1), 155-167. Recuperado de https:// journals.openedition.org/cadernosaa/1068

Sansi, R. (2016). Experimentaciones participantes en arte y antropología. Revista De Dialectología y Tradiciones Populares, 71, 67-73. doi: 10.3989/rdtp.2016.01.001.06

Sillitoe, P. (2007). Anthropologists only need apply: challenges of applied anthropology. Journal of the Royal Anthropological Institute, 13(1), 147-165. doi: 10.1111/j.1467-9655.2007.00418.x

Stavenhagen, R. (1992). Cómo descolonizar las ciencias sociales". En M. Salazar (ed.). La investigación acción participativa. Inicios y desarrollos (pp. 37-64). Madrid: Popular.

Uribe Oyarbide, J. M. (2015). Antropología aplicada: Momentos de un debate recurrente. Etnografías Contemporáneas, 1(1), 26-57. Recuperado de http://hdl.handle.net/2454/21515

Velasco, H.; Díaz de Rada, A. (1997). La lógica de la investigación etnográfica. Madrid: Trotta.

Weidman, H. (1978). Yendo de "aquî́" para “allî". En R. Sánchez Molina (ed.), La Etnografía y sus aplicaciones. Lecturas desde la Antropología Social y Cultural (pp. 267-278). Madrid: Editorial Universitaria Ramón Areces. 